\title{
Evaluation of Solar Potential at Niamey: Study Data of Insolation from 2015 and 2016
}

\author{
Maigargue Dankassoua1, Saïdou Madougou1 ${ }^{*}$, Saleye Yahaya² \\ ${ }^{1}$ Laboratory of Energetic, Electronics, Electrotechnics, Automation and Industrial Computing (LEA2EI), \\ University Abdou Moumouni of Niamey, Niamey, Niger \\ ${ }^{2}$ National Center of Solar Energy (CNES), Niamey, Niger \\ Email: *nassara01@yahoo.fr
}

How to cite this paper: Dankassoua, M., Madougou, S. and Yahaya, S. (2017) Evaluation of Solar Potential at Niamey: Study Data of Insolation from 2015 and 2016. Smart Grid and Renewable Energy, 8, 394-411.

https://doi.org/10.4236/sgre.2017.812026

Received: November 6, 2017

Accepted: December 22, 2017

Published: December 25, 2017

Copyright (c) 2017 by authors and Scientific Research Publishing Inc. This work is licensed under the Creative Commons Attribution International License (CC BY 4.0).

http://creativecommons.org/licenses/by/4.0/

\section{(c) (i) Open Access}

\begin{abstract}
Solar energy is a very abundant renewable energy source during the day. The solar energy received in a given point of the Earth is function of the time, the season and the latitude of the point. It has been proven that the solar energy received in one day by our planet is thirty times higher than the annual global energy consumption. Africa is one of the sunniest continents of the world. Nowadays, solar energy is attracting particular attention in the implementation of the energy policies. This renewable source is a key solution to world energy problems, especially in the context of global warming. Niger is identified as among the sunniest zones of the World. Knowledge of solar potential is one of the crucial parameters to master for energy applications. In this study, continuous measurements (at intervals of 5 minutes over 24 hours) of solar radiation have been carried out on the site of the National Center of Solar Energy of Niamey. These measurements were taken using the pyranometers, allowed us to collect the values of the daily global sunshine on a horizontal plane and on an inclined plane of the years 2015 and 2016. The treatment and the exploitation of these data allowed us to determine the daily and monthly duration of sunshine, then the impact of the clouds and dust on the solar radiation, to evaluate the solar potential of the site and determine the variations of this solar potential as a function of time. The results showed that the solar potential was very favorable for many solar applications.
\end{abstract}

\section{Keywords}

Solar Energy, Sunning, Solar Potential, Energy Application, Solar

Photovoltaic, Solar Thermals

\section{Introduction}

Since the industrial revolution, the world has known an important economic 
development which generated a very significant increase in energy demand [1] [2]. This boom has been mainly covered by the use of fossil and fissile energy sources which are exploited in an abusive way. Unfortunately, this overexploitation will soon lead to their exhaustion and their end [2]. Moreover, the exploitation of the fossil energy sources was not without consequences on the environment. As a result, climate warming has become a major global issue [3]. The challenge is, therefore, to ensure the world's energy demand without increasing global greenhouse gas emissions. In this context, today, renewable energies appear, to be the ultimate solution with this challenge. Renewable energies abound in the world and make the pride of the countries which have them and exploit them. Solar energy is an abundant and inexhaustible renewable energy source, which is useful in human life. In a single day, the Earth receives solar energy of about $1.6 \times 10^{18} \mathrm{kWh} /$ year, the equivalent of 30,000 times the world energy consumption needs [4]. In Niger, many estimates, but without real measurements on the ground, indicate the existence of an important potential and its occurrence over the whole the country. However, the knowledge of the solar potential is an essential parameter for the implementation of its applications. It is therefore, necessary to have solar potential data from in situ measurements. This paper presents the results of an evaluation of the solar potential in Niamey based on real data of measurements through the years of 2015 and 2016. We first present the problem, followed by materials and methods. Next, we expose the results and finish with the conclusion and the perspectives.

\section{Literature Review}

The control of the random nature of renewable energy sources, particularly solar energy, could make it possible to the power network operators to better exploit them and use them. The sizing and optimal management of a solar system [5] necessarily involves perfect knowledge of the solar radiation arriving on the ground in a given medium.

The value of the solar radiation at a point on the ground and a given moment depends not only on the position of the Sun, but also on the optical state of the atmosphere. Before reaching the ground, the incidental solar radiation is strongly influenced by the terrestrial atmosphere through interactions of standard absorption and reflection. The total solar radiation on the ground is composed of two distinct parts: a direct component which depends only on the distance between the point of measurement and the Sun: it is the direct radiation, and a diffuse component which depends on the state of the cloud cover, the ozone rate, the aerosols, the water content, etc. As a renewable energy source, solar energy is a climatic resource from which we must benefit, passively and/or actively, through the production of electricity or other applications. If there is one sub-sector of energy where Niger must legitimately put a particular emphasis, it is well that of solar energy, because it has significant sunshine all over its territory and throughout the year. Niger is among the sunniest countries of the world 
[6]. The valorization of solar energy in Niger is one of the most appropriate solutions to the energy crisis that is plaguing the country. Indeed, the social indicators as regards access to energy are among weakest of the world. In 2014, the rate of access to electricity in Niger is $10 \%$, while that of access to the modern energy for cooking is only $1 \%$, for a growth rate of the population of $3.9 \%$ per year [6] [7]. To raise these indicators of access to the energy and so much well of others, Niger needs to effectively emphasize its potential of solar energy. However, the effective application of this solar potential requires initially the perfect knowledge of its data in space and time. Therefore, there is need for thorough and detailed studies of the solar energy potential throughout the world. This study falls within this framework of action.

In the solar energy potential assessment at the Sahelian band, only a few studies have been really conducted. We can cite the study conducted by $\mathrm{B}$. Ould Bilal et al. (2007) on the study and modeling of the solar potential of the Nouakchott and Dakar sites. The results that authors obtained show that, at each site, the solar radiation measured and calculated has the same allure. A comparative study conducted by the authors has led a fairly good correspondence between the solar radiation of Dakar and Nouakchott. The evaluation of available solar energy shows that the worst months are December for Nouakchott and February for Dakar, with respective irradiations of $4.9 \mathrm{kWh} / \mathrm{m}^{2}$ and $4.37 \mathrm{~kW} / \mathrm{m}^{2}$ [8]. The second study to emphasize is that of M. Dankassoua et al. (2017) where the authors studied the global solar radiation in Niamey from the pre-monsoon and the monsoon period of the year 2013 (May to October). In this study, it appears from the analysis of the results a good correlation between the measured results of global solar radiation and these's calculated with the models. It also implies that Niamey area has a good insolation [6]. The last study is for Abdoulatif Bonkaney et al. (2017). In this paper, authors studied the impacts of cloud cover and dust on the performance of photovoltaic module in Niamey. Results show that dust accumulation has a great effect on decreasing the daily energy yield of the unclean module [9]. But this effect is a long-term effect. For the cloud cover, the effect is immediate. All of these studies show that the Sahelian band has good potential, but all of these studies are done over a very short period. This does not confirm the reliability of the results obtained and also know the contours of their daily, monthly, annual and seasonal variations.

\section{Materials and Method}

\subsection{Site of Measurements}

The data collection is carried out at the National Center of Solar Energy (CNES) in the city of Niamey from January 2015 to December 2016. Figure 1 shows the position of Niamey city on the map of Niger.

The geographical coordinates (latitude, longitude and altitude) of the site are given in Table 1. 


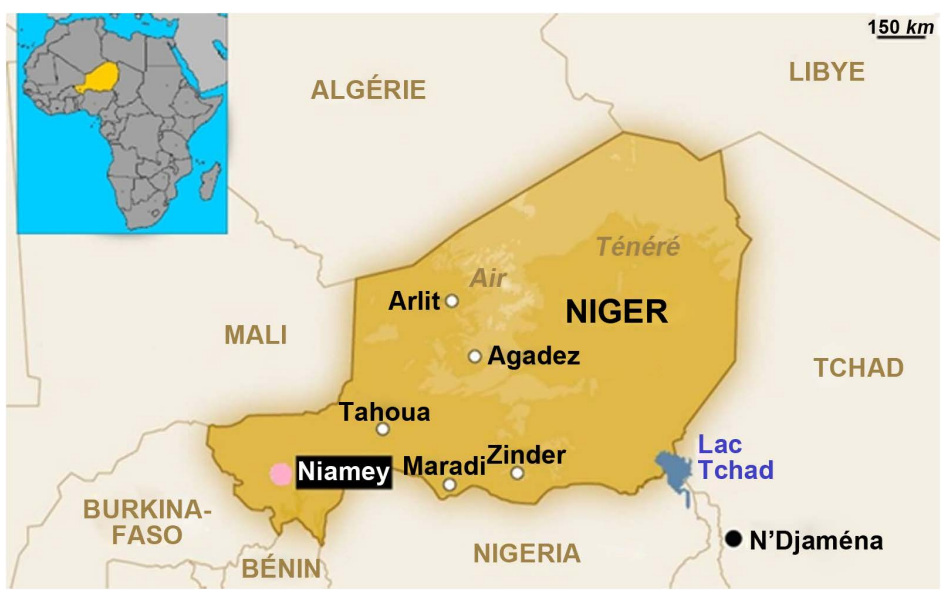

Figure 1. Position of Niamey city on the map of Niger.

Table 1. Geographical coordinates of the site of measurements.

\begin{tabular}{cccc}
\hline Site of measurements & Longitude $\varphi\left(^{\circ}\right)$ & Latitude $\theta\left(^{\circ}\right)$ & Altitude Z (m) \\
\hline CNES & $2^{\circ} 11^{\prime}$ East & $13^{\circ} 50^{\prime}$ North & 213 \\
\hline
\end{tabular}

\subsection{Materials of Measurements}

To evaluate the solar potential, we collected the data of the solar radiation (irradiation in $\mathrm{W} / \mathrm{m}^{2}$ ) during the years of 2015 and 2016. These data result from measurements using two pyranometers and their accessories installed at the National Centre of Solar Energy of Niamey. The duration of insolation is a classical weather data, measured using a heliograph. The examination of the bands heliographs is done according to the established standards. The total Radiation is measured using a pyranometer with integrator ELSB-2 [6] [10], with digital displays, which integrate the values of the total solar radiation per day. The devices are installed on the roof of a building on concrete bases, to approximately $5 \mathrm{~m}$ height in places released well in order to avoid the shadow by the surrounding objects (Figure 2).

\subsection{Installation of Materials}

\subsubsection{Establishment of the Supports}

This operation consists of well positioning the wooden supports in the desired orientation. The ideal orientation of the solar collectors is full South in the Northern hemisphere (full North in the Southern hemisphere) so that the sunshine arrive perpendicularly to the collectors so that they receive the maximum of sunlight. A variation of $15^{\circ}$ towards the East or the West can be accepted since the output of the system decreases very appreciably. Thus, we chose the Southern orientation full for our two solar collectors during all measurements.

\subsubsection{Fixing the Solar Collectors}

In this second operation, the two pyranometers are mounted and screwed onto the supports. A thermometer of contact, placed below the radiometer, measures the temperature of the ambient air [11]. 

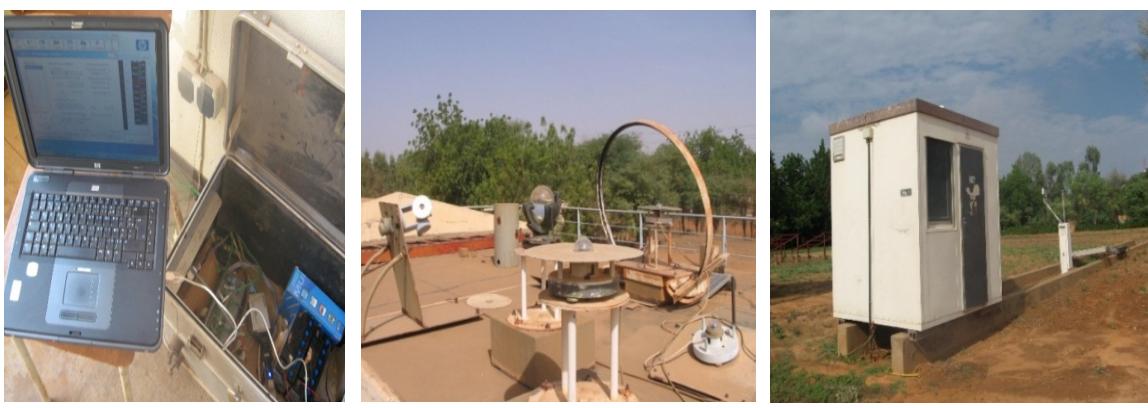

Figure 2. The devices are installed on the roof of the building of the CNES and the shelter of protection of the base of data recording on the spot.

\subsubsection{Adjustment the Horizontality}

A spirit level is used to monitor horizontality for measurements on the horizontal plane.

\subsubsection{Adjustment of the Inclination}

An inclinometer (a rule of $50 \mathrm{~cm}$ provided with a spirit level and a mobile disc graduated in degree) is used to monitor the inclination for measurements on the inclined plane.

\subsubsection{Measurement Principle of the Pyranometer}

The pyranometer is intended to measure global solar radiation at short wavelengths in the spectral range from 300 to $2800 \mathrm{~nm}$. The thermopile detector measures the luminous flux up to $2000 \mathrm{~W} / \mathrm{m}^{2}$, with a response time of less than 18 seconds and a sensitivity usually estimated at $10 \mu \mathrm{V} / \mathrm{W} / \mathrm{m}^{2}$ and varies $\pm 5 \%$ from $-10^{\circ} \mathrm{C}$ to $+40^{\circ} \mathrm{C}$. The operating temperature range is from $-40^{\circ} \mathrm{C}$ to $+80^{\circ} \mathrm{C}$ and the stability is over $1 \%$ per year [6]. The pyranometers have as the measurement accuracies: directional error $<20 \mathrm{~W} / \mathrm{m}^{2}$, tilt error $<3 \%$ and expected daily uncertainty $<10 \%[11]$.

\subsubsection{Connections}

The first connection consists of connecting the radiometer to bill-poster-recorder METEON via a cable. The second connection consists to join the bill-poster-recorder to the Laptop via the USB interface cable [12].

\subsection{Method of Data-Gathering}

After performing the previous operations, the bill-poster-recorder is started to allow observing and instantly recording the measurements on the Laptop. Two windows appear on the Laptop screen. One allows searching the stored measurements on the Laptop and viewing them. The second window is used to calibrate the sensitivity of the radiometer, to set the date, time and recording intervals of the measurements. After setting the measurement period, the bill-poster-recorder stores the values of the overall illumination. Once the measurements begin, the measured data can be viewed at any time without any inconvenience and copied to other discs. 


\section{Presentation, Analysis and Interpretation of the Results}

\subsection{Clearness Index}

Figure 3 presents the values of the clearness index $(\mathrm{Kt})$ at Niamey for the year 2015.

The values of Kt lie between 0.50 and 0.61 , what proves that the atmosphere is turbid during the year. The lowest value is obtained in August which corresponds to the period of highest rainfall. This is explained by the presence of water molecules in the atmosphere and to the effect of albedo by the clouds. The maximum value 0.61 indicates the presence of the impurities in the atmosphere. Indeed the Sahelo-Saharan area is characterized by an atmosphere rich in aerosols of all sizes. Their concentration is, however, stronger during the dry season (December-March) than during the wet season (May-October) where the atmosphere undergoes a light purification by rainwater. These results of clearness index confirm those obtained by Abdoulatif Bonkaney et al. (2017) [9].

\subsection{Fraction of Insolation}

Figure 4 illustrates the variation of the rate of insolation during the year 2015.

The rate of insolation (relationship between the duration of real insolation $S$ and the total duration of insolation $S_{0}$ ) varies between 0.48 and 0.99 . The average is of 0.89 . This strong rate shows that the solar layer with Niamey would be important.

\subsection{Daily Average Profile of the Global Irradiance on a Horizontal Plane}

Figures 5(a)-(1) show the daily average (standard days) profile of the global irradiance on a horizontal plane of the different months in 2015.

These figures show the importance of the global irradiance on a horizontal plane owing to the fact that they correspond to the standard day of each month of the 2015. They present the maximum values of global solar radiation close to the average values of each month, thus giving a good estimate of the solar potential of each month. Values that exceed $600 \mathrm{Wh} / \mathrm{m}^{2}$ are obtained between 1

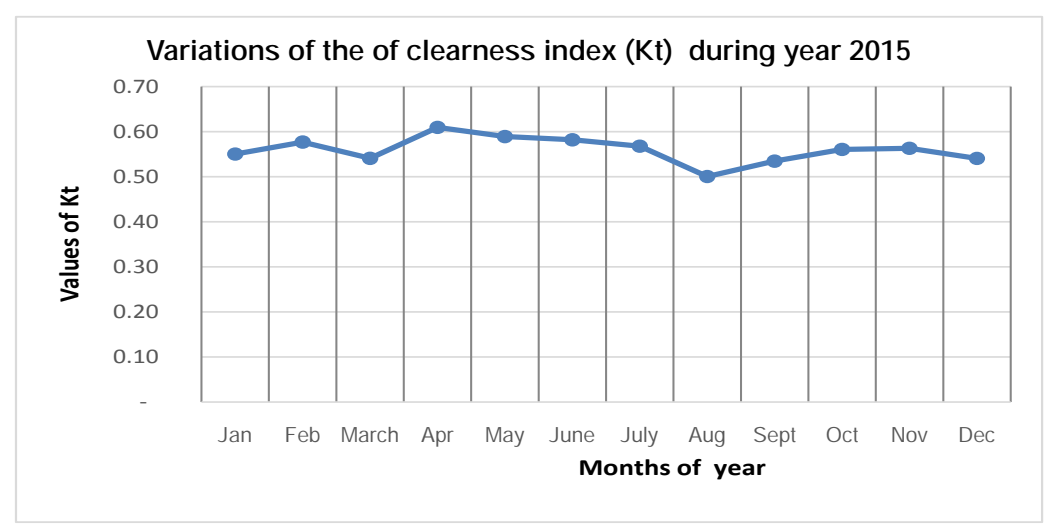

Figure 3. Variation of clearness index during the year 2015. 


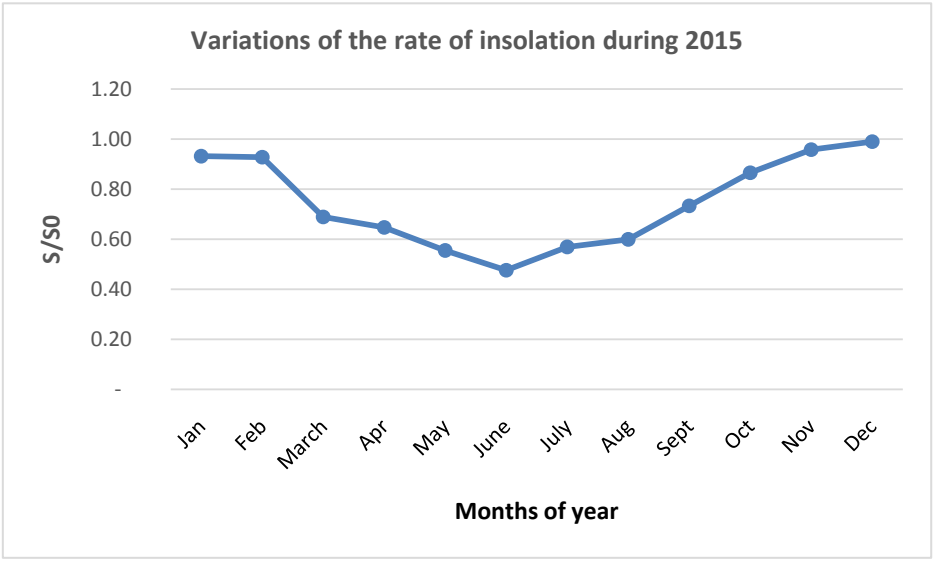

Figure 4. Variation of the rate of insolation in 2015.

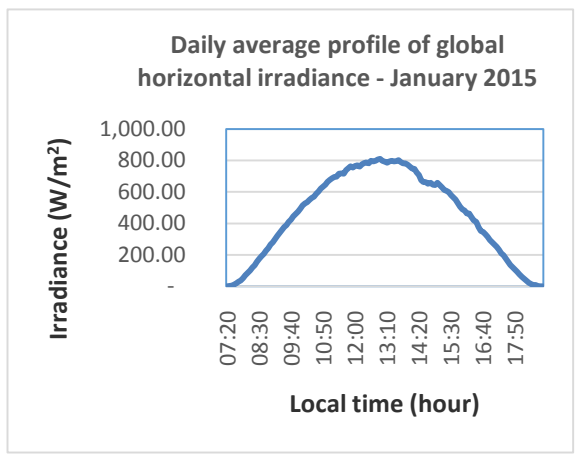

(a)

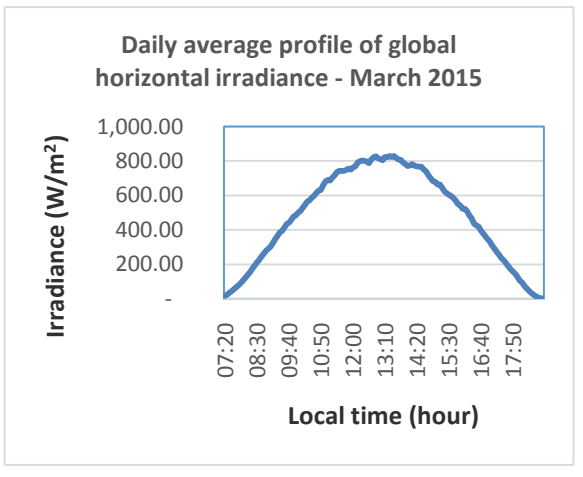

(c)

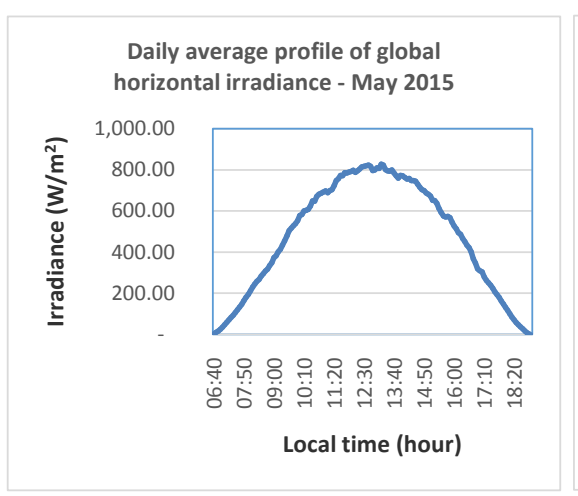

(e)
Daily average profile of global horizontal irradiance - February 2015

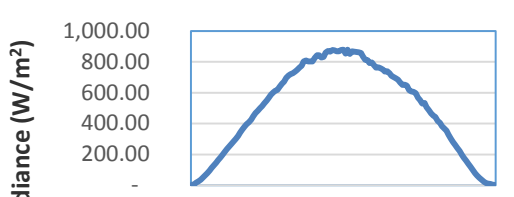

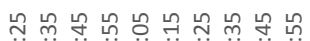

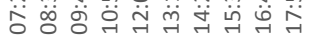
Local time (hour)

(b)

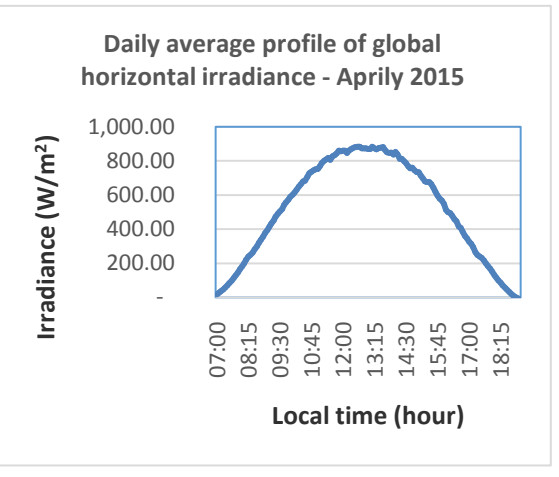

(d)

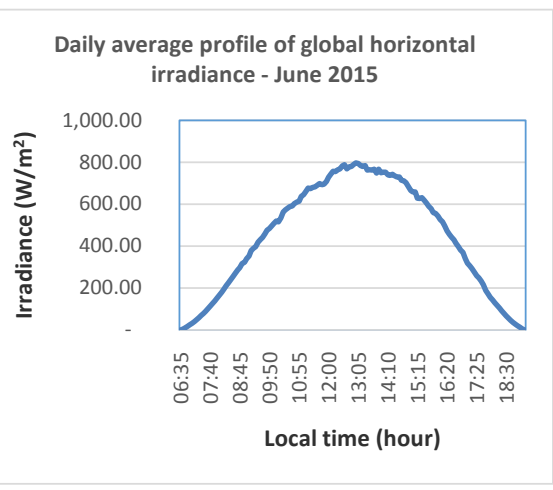

(f) 


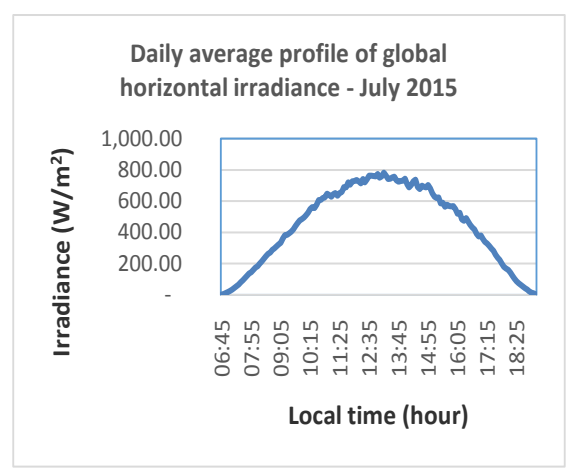

(g)

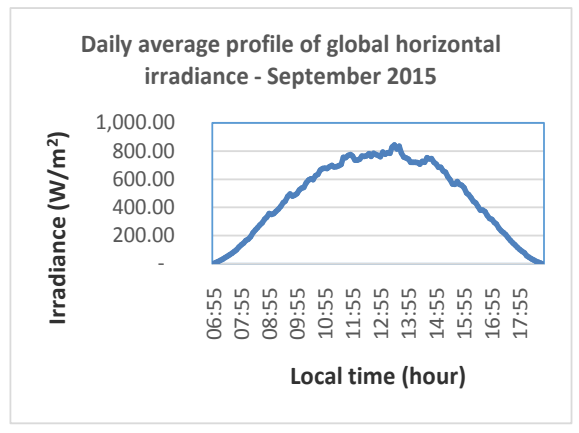

(i)

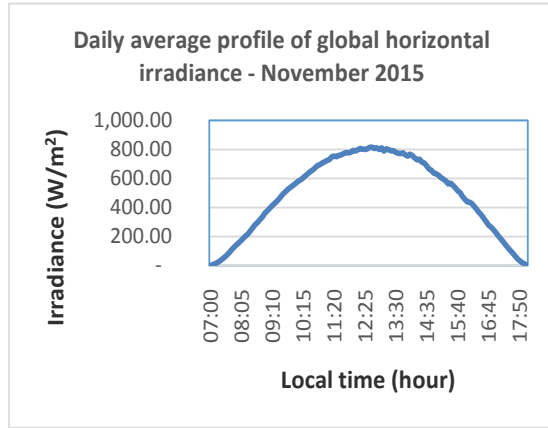

(k)

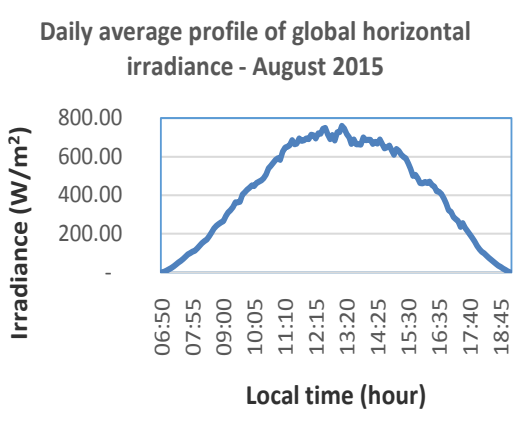

(h)

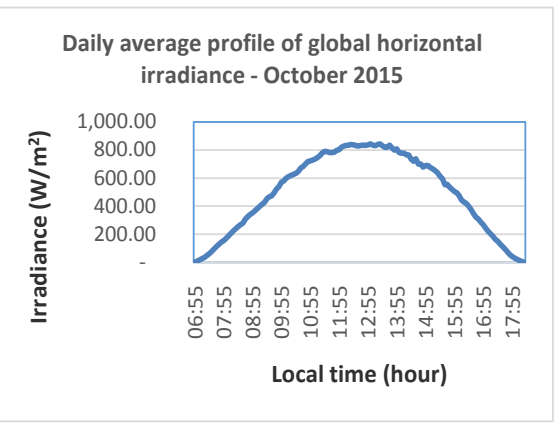

(j)

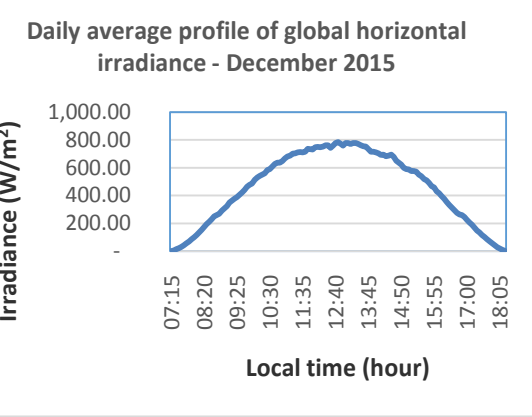

(1)

Figure 5. (a)-(1): Daily average profile of the global irradiance on a horizontal plane for different months of 2015.

PM and 2 PM. Between 10 AM and 4 PM the values of solar radiation exceed $500 \mathrm{Wh} / \mathrm{m}^{2}$. These results are similar to those found by M. Dankassoua et al. (2017) in the study of global solar radiation conducted in Niamey for the pre-monsoon and the monsoon periods of during the year 2013 [6].

Figures 6(a)-(1) show the daily average profile of the global irradiance on a horizontal plane of the different months in 2016.

The year 2016 presents also an important irradiance in Niamey. These results testify to this strong solar potential. The figures above show characteristics similar to those in 2015 but with maxima which reach the $800 \mathrm{Wh}$. The potential is as important as that of the study of M. Dankassoua et al. (2017) of the year 2013 [6]. 


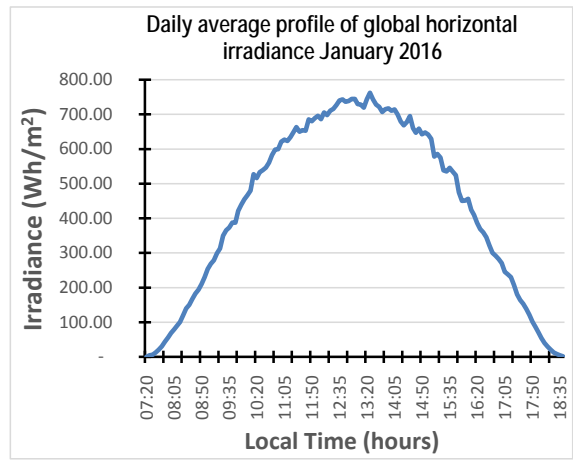

(a)

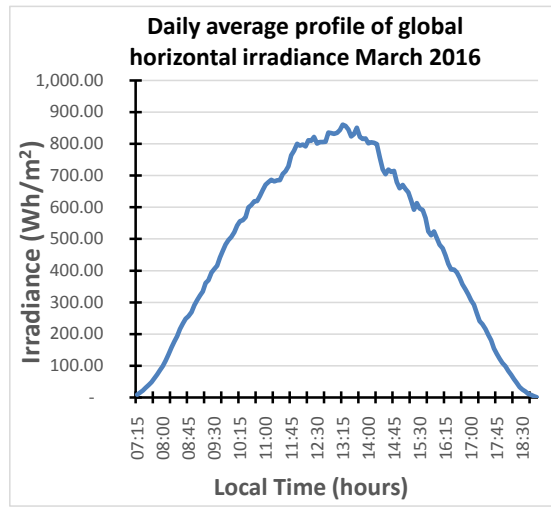

(c)

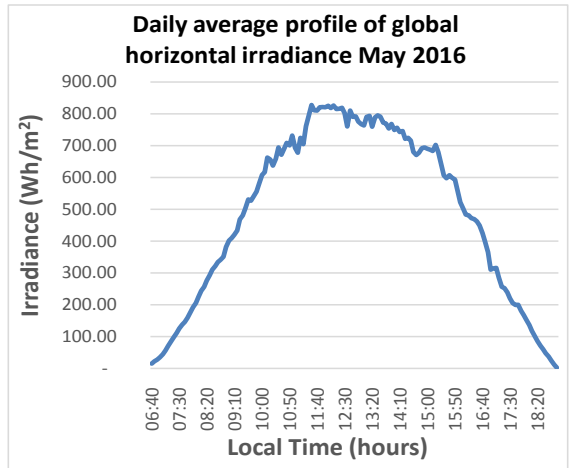

(e)

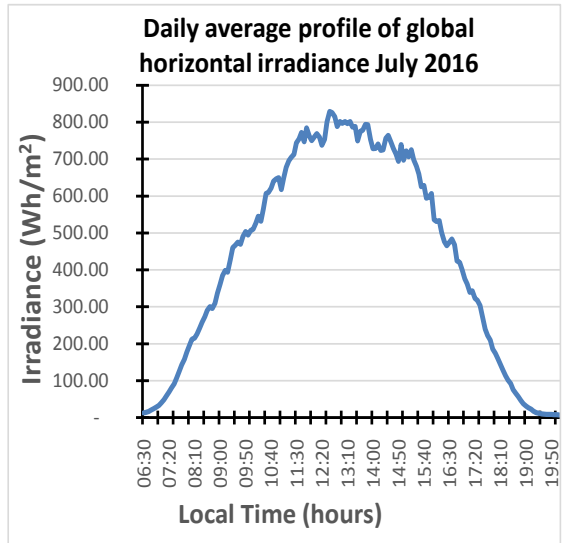

(g)
Daily average profile of global horizontal irradiance February 2016

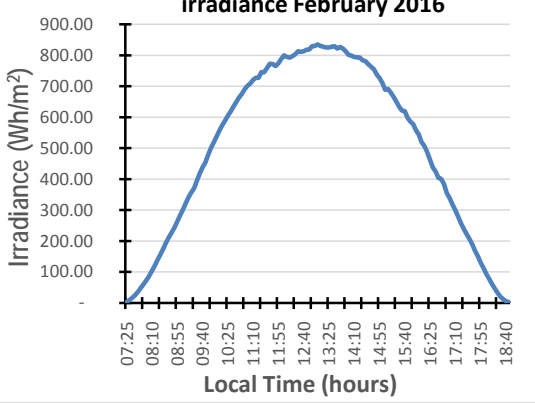

(b)

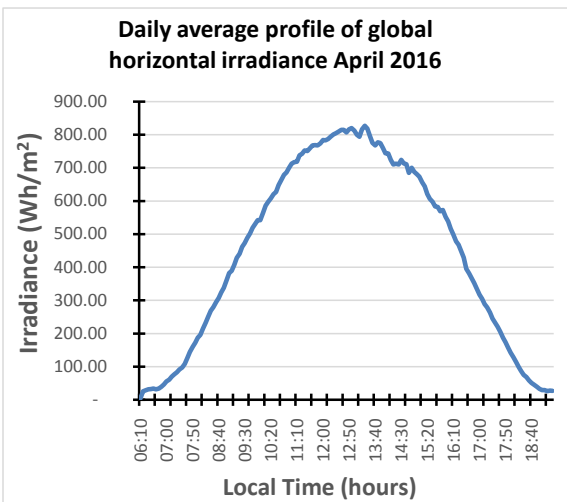

(d)

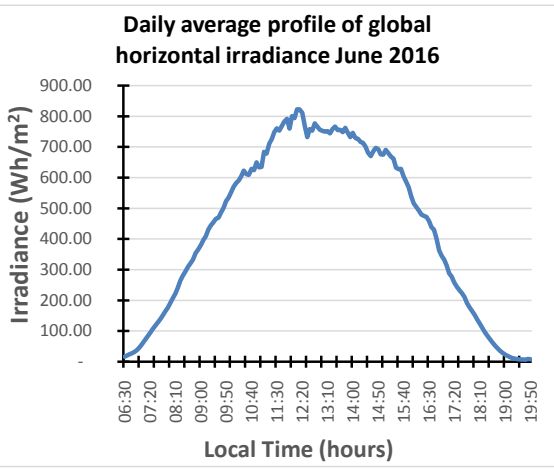

(f)

Daily average profile of global horizontal irradiance August 2016

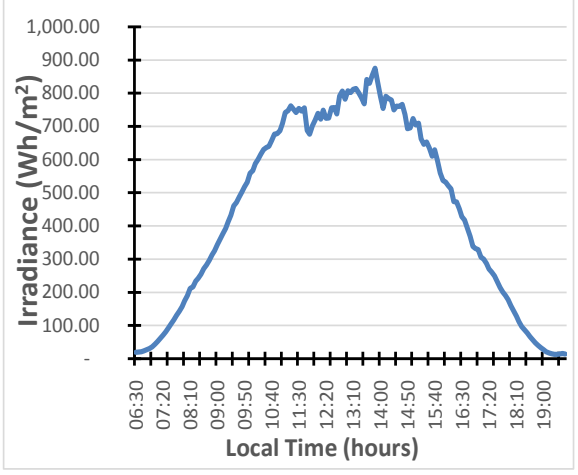

(h) 


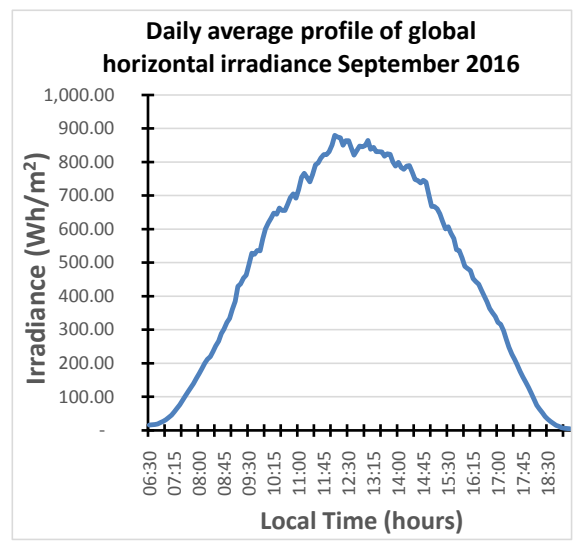

(i)

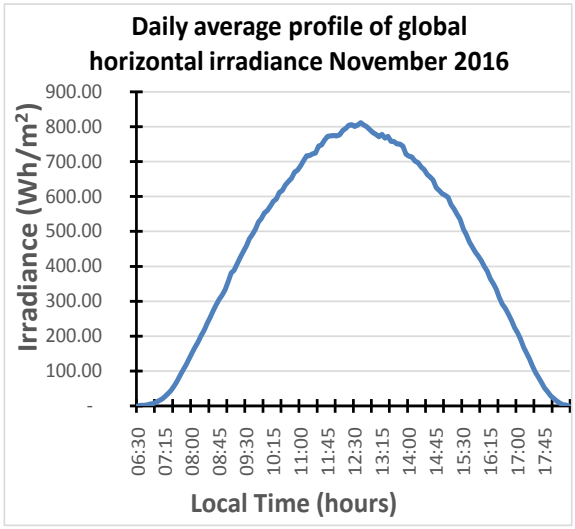

(k)

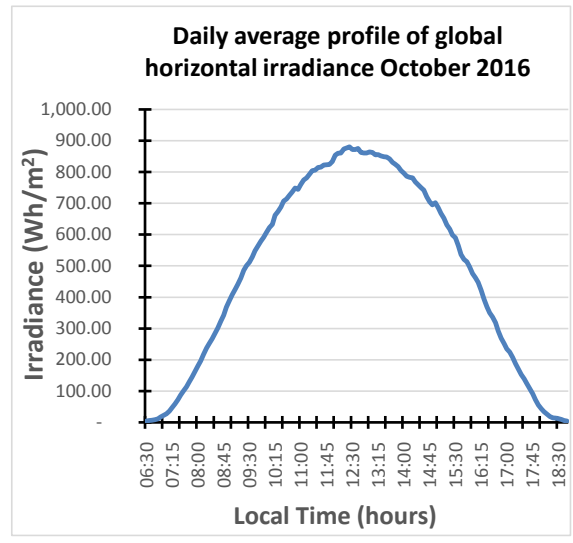

(j)

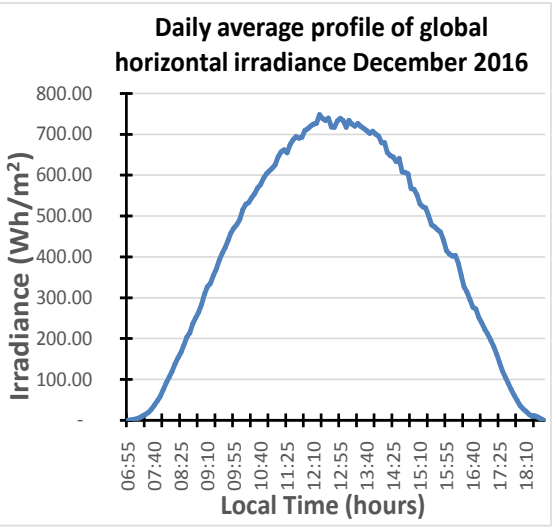

(l)

Figure 6. (a)-(l): Daily average profile of the global irradiance on a horizontal plane in 2016.

\subsection{Monthly Variations of Average Values of Total Sunning on a Horizontal and Inclined Plane}

The Figure 7 show monthly variations of average values of solar radiation (a) on a horizontal plane and (b) on an inclined $\left(15^{\circ}\right)$ plane at Niamey during the 2015.

Figure 7 and Figure 8 show the monthly variations of the average values of the total sunning (a) on a horizontal plane and (b) on an inclined $\left(15^{\circ}\right)$ plane in Niamey point in 2015 and 2016. These values range between 5 and $6 \mathrm{kWh} / \mathrm{m}^{2}$. The minimal and maximum values are given by Figure 9. April is shown to here the highest values, its maximum sunning being able to exceed the $7 \mathrm{kWh} / \mathrm{m}^{2}$ and the minimum exceeding the $3 \mathrm{kWh} / \mathrm{m}^{2}$. The low values correspond to the months of heavy rainfall July to September.

Figure 9 also show that August presents, in the two years, a minimum of low sunning. The decrease is due to the climatic characteristics of this month compared to other months. Indeed, the month records the most precipitations in Niger. The presence of the clouds attenuates the value of the sunning on the ground as it is shown in Figures 10(a)-(d). 


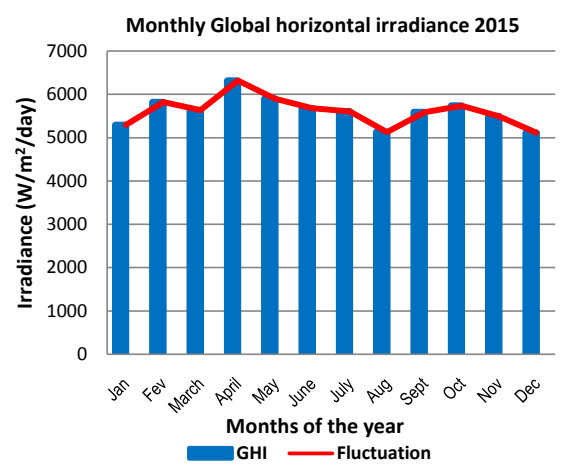

(a)

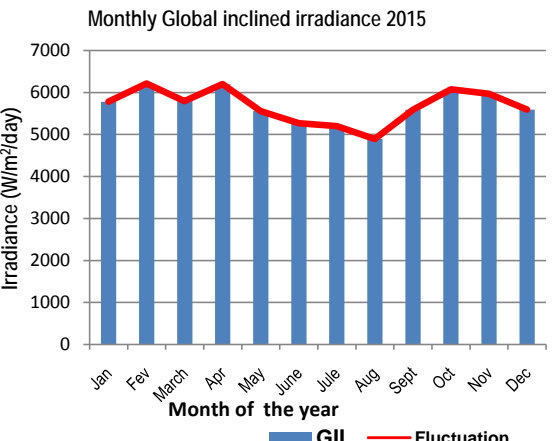

(b)

Figure 7. Monthly variations of average values of total sunning (a) on a horizontal plane and (b) on an inclined $\left(15^{\circ}\right)$ plane in Niamey in 2015.

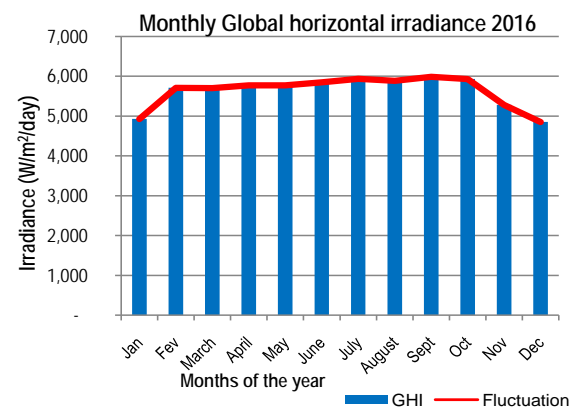

(a)

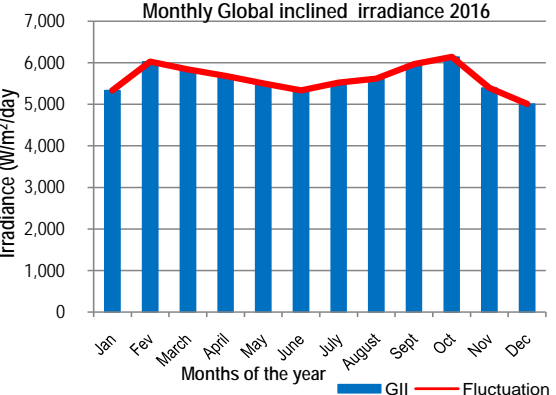

(b)

Figure 8. Monthly variations of average values of total sunning (a) on a horizontal plane and (b) on an inclined $\left(15^{\circ}\right)$ plane in Niamey in 2016.

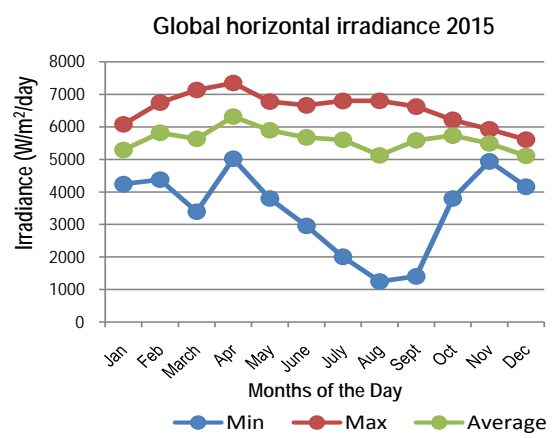

(a)

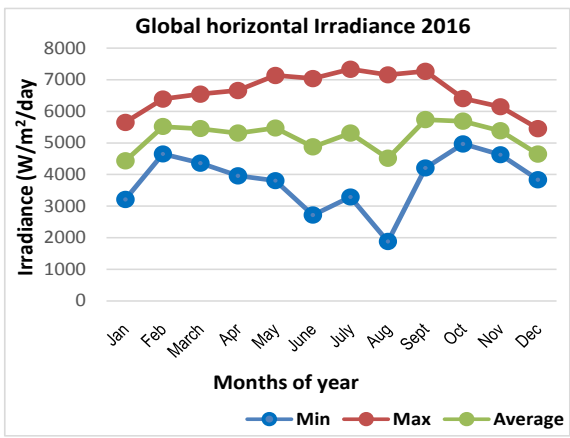

(b)

Figure 9. Monthly variations of the Maximum, Average and Minimum of total sunning on a horizontal plane in 2015 and in 2016.

\subsection{Influence of the Sky Conditions on the Solar Radiation}

Figures 10(a)-(d) show the impact of the clouds and dust on the solar radiation.

On figures 10, the passage of clouds between 11 am to $1 \mathrm{pm}$ in (Figure 10(a)) and 11 am to $7 \mathrm{pm}$ in (Figure $10(\mathrm{c})$ ) is felt to the measure of the radiation. In the same way at the moment of rainfall (Figure 10(b) and Figure 10(d)) between 12 am to $6 \mathrm{pm}$, three radiations: Global horizontal (GH), Global tilted (GI) and the Diffuse one (D) are influenced by the presence of dust and rain. 


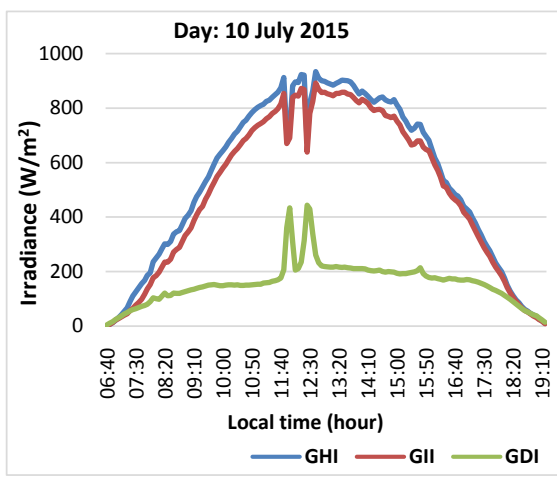

(a)

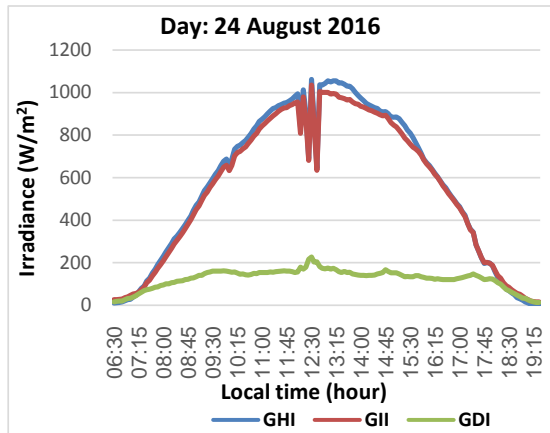

(c)

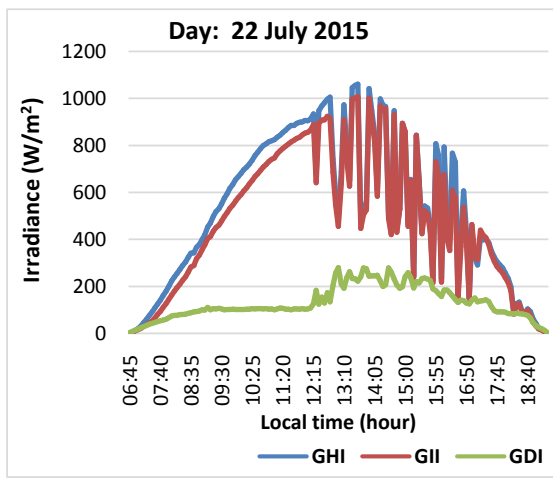

(b)

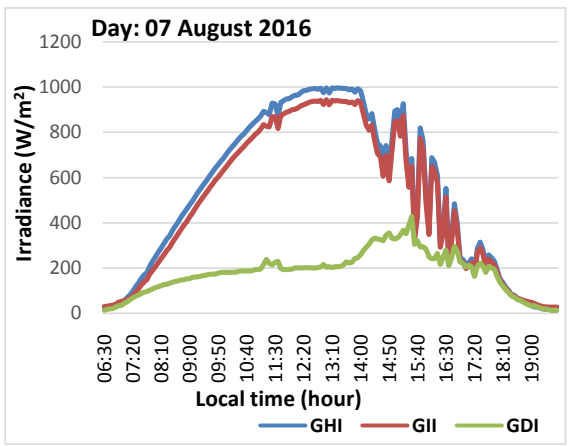

(d)

Figures 10. The impact of the clouds and dust on the solar radiation: In 2015, (a): between 11 am - 1 pm, passage of the clouds; (b): between 12 am and 5 pm, rain and dust. In 2016; (c): between 11 am - 1 pm passage of clouds; (d): between 1 pm and 7 pm, rain and dust.

There is also an increase in Diffuse when the sky is overcast. These results confirm those obtained by Abdoulatif Bonkaney et al. (2017) [9].

When the sky is clear, the radiation is less disturbed. Figures 11(a)-(d) show the evolution of the three radiations during the day when the sky is clear.

The figures above inquire the optical state of the atmosphere. When it is slightly polluted the curves appear smoother. This is the case of the Figure 11(b) where the atmosphere is purified of its aerosols by the action of rainwater from the wintry period in July through August.

\subsection{Seasonal Variations of Total Sunning on Horizontal Plane and Tilted Plane}

Figure 12(a), Figure 12(b) show the seasonal variations of the total sunning on the horizontal Plane (GHI) and on the tilted plane (GII) in 2015 and 2016. These seasonal variations had an influence on the energy received by the solar panels.

Figure 12(a), Figure 12(b) show the monthly variations of the total sunning on a horizontal plane and on an inclined plane during the year 2015 and the year 2016. We note that from September to March, the daily irradiation is greater on the $15^{\circ}$ inclined plane than on the horizontal plane. By cons, between March and September the phenomenon is reversed. 


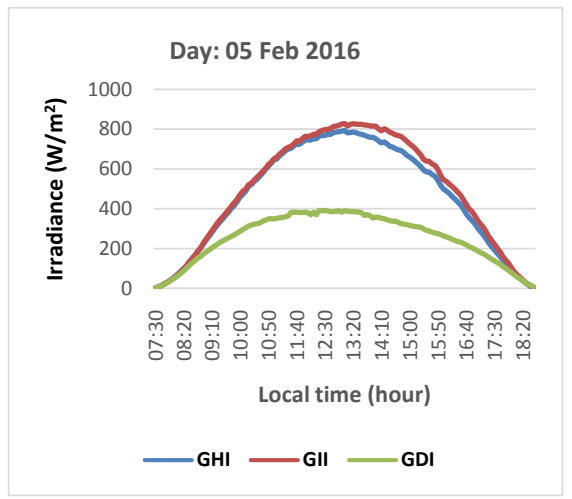

(a)

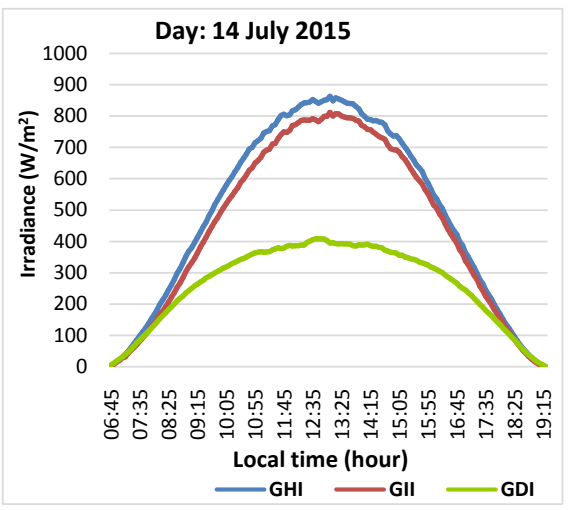

(c)

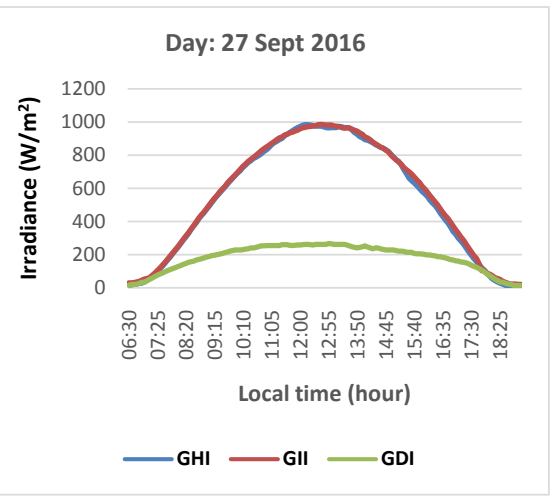

(b)

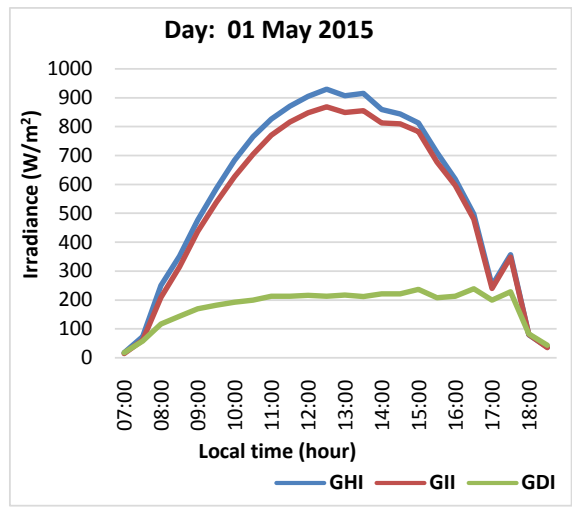

(d)

Figures 11. Evolution of the three radiations during the day, (a), (b), (c) in clear sky; (d) in clear sky and shades at $5 \mathrm{pm}$.

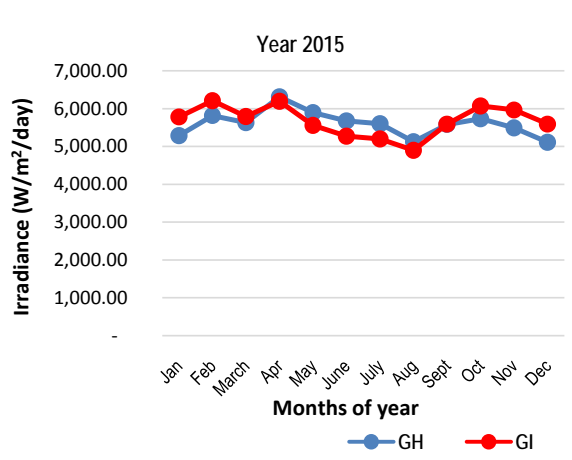

(a)

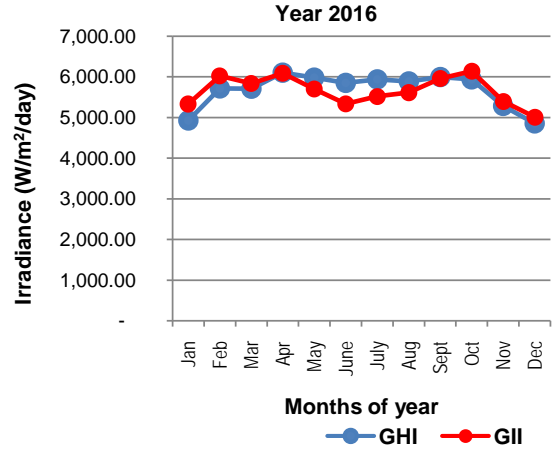

(b)

Figure 12. (a), (b): Seasonal variations of the total sunning on the horizontal plane (GHI) and on an inclined plane (GII) in 2015 and 2016.

Figures 13(a)-(1) show daily variations of the total sunning on a horizontal plane and on an inclined plane during each month in 2015.

Figures 14(a)-(1) show daily variations of the total sunning on a horizontal plane and on an inclined plane during each month in 2016.

Figure 13 and Figure 14 show how the global sunning of the two years evolves on a horizontal plane (GHI) and on an inclined plane at $15^{\circ}$ (GII). From 


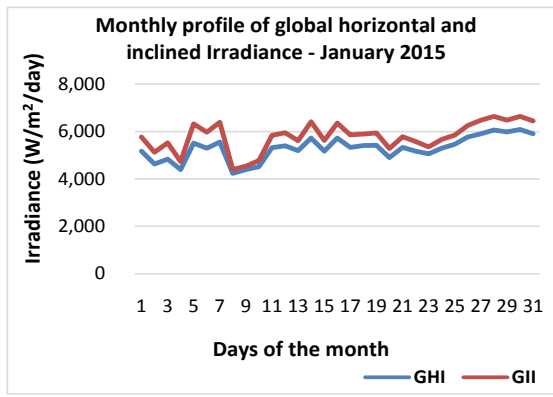

(a)

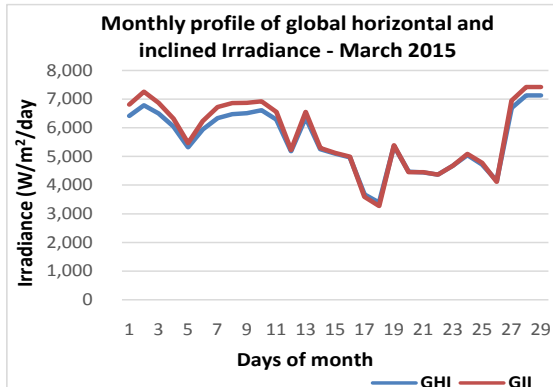

(c)

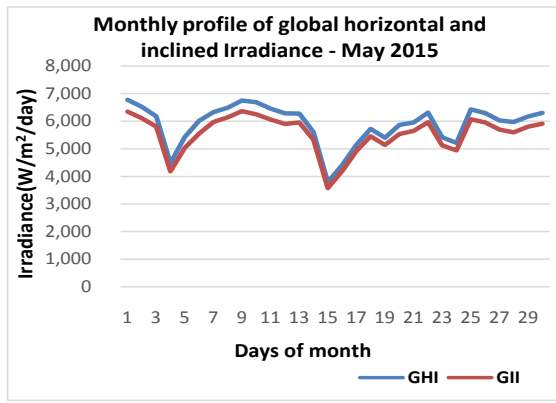

(e)

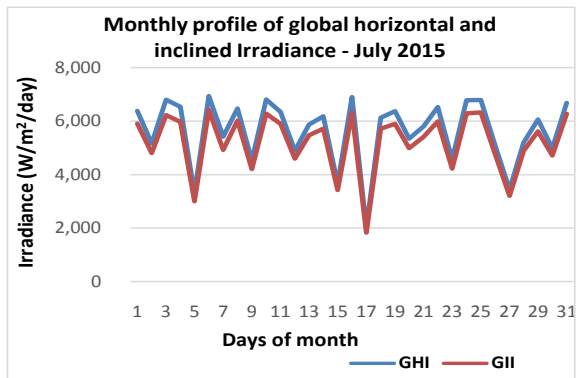

(g)

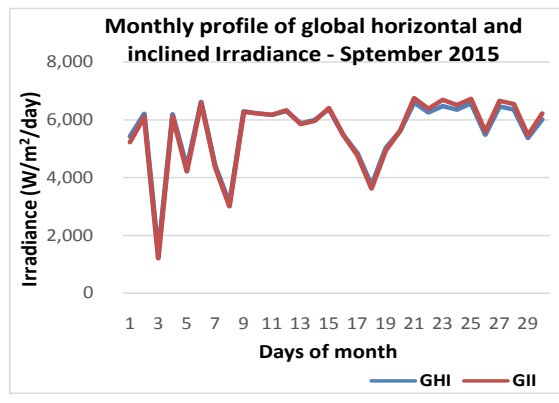

(i)

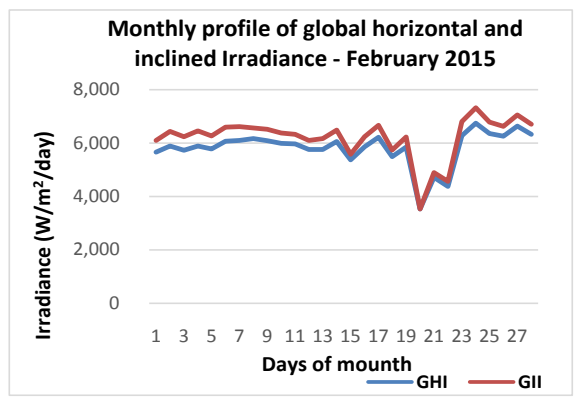

(b)

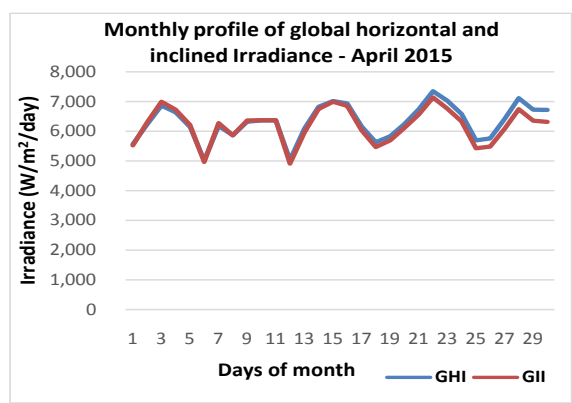

(d)

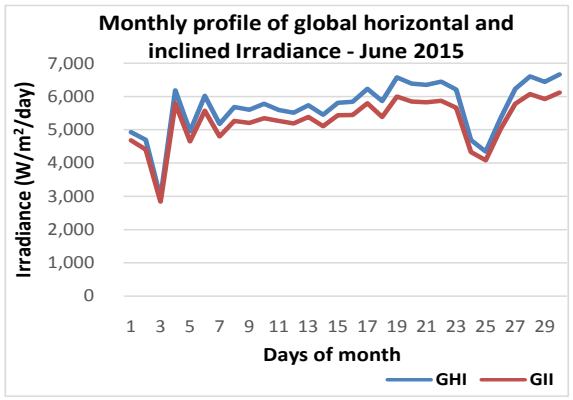

(f)

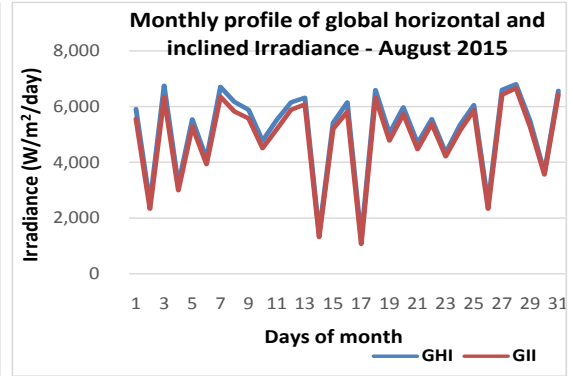

(h)

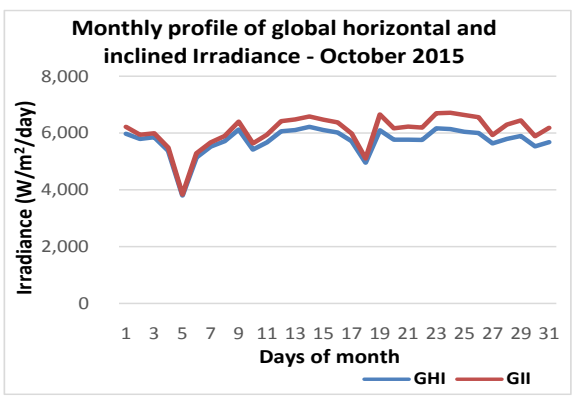

(j) 


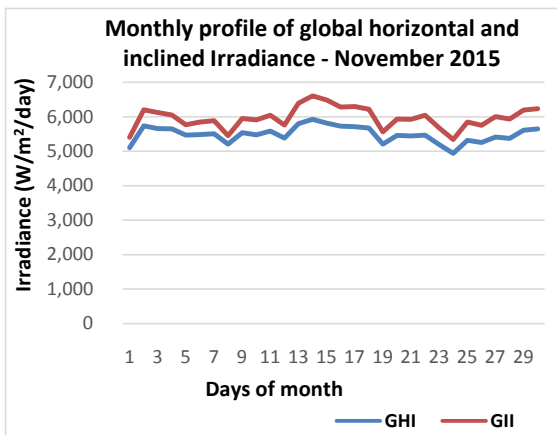

(k)

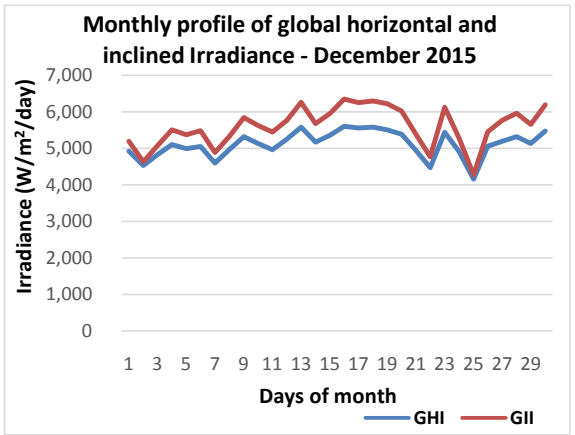

(l)

Figure 13. (a)-(1): Daily variations of the total sunning on a horizontal plane and on a tilted plane $\left(15^{\circ}\right)$ in 2015 .

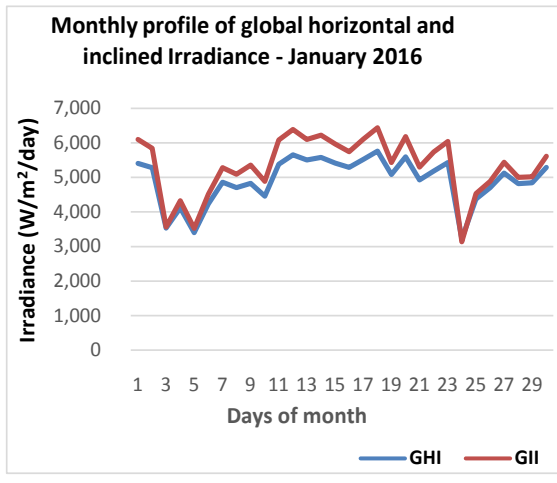

(a)

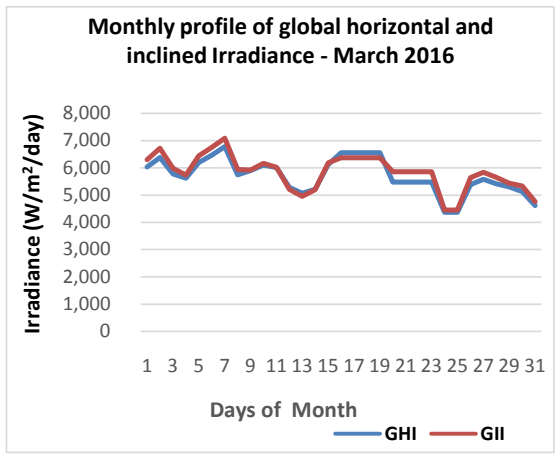

(c)

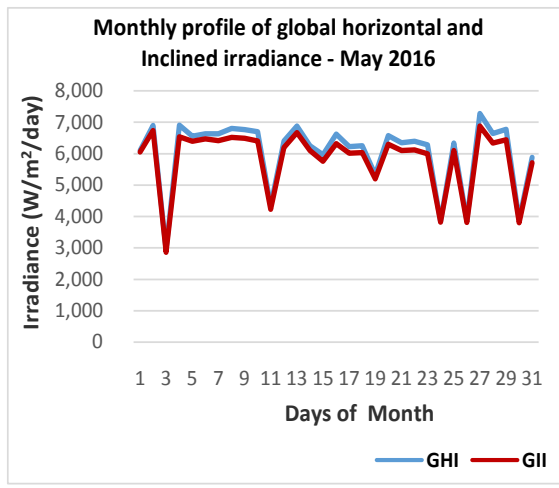

(e)

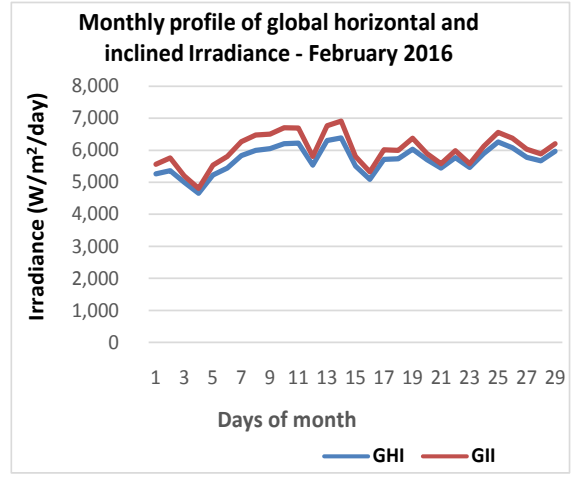

(b)

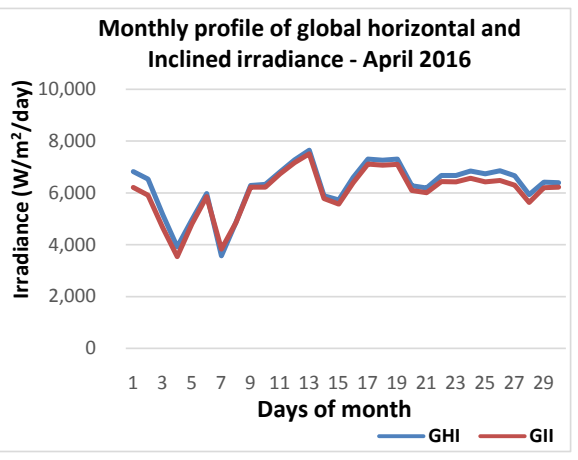

(d)

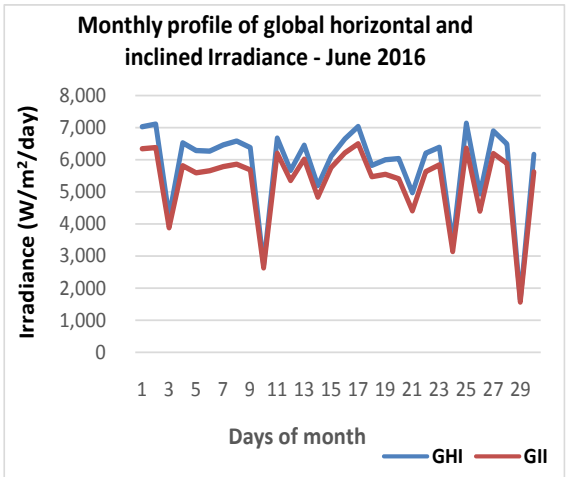

(f) 


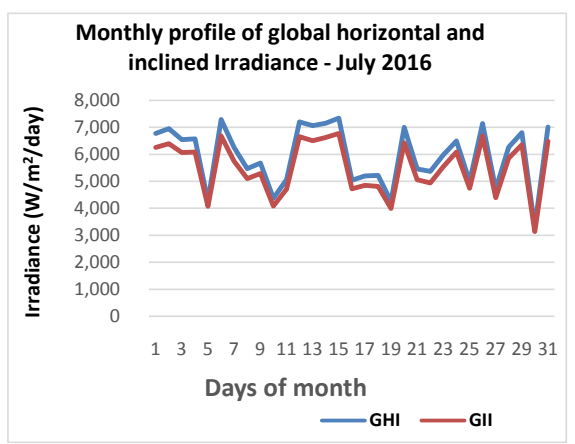

(g)

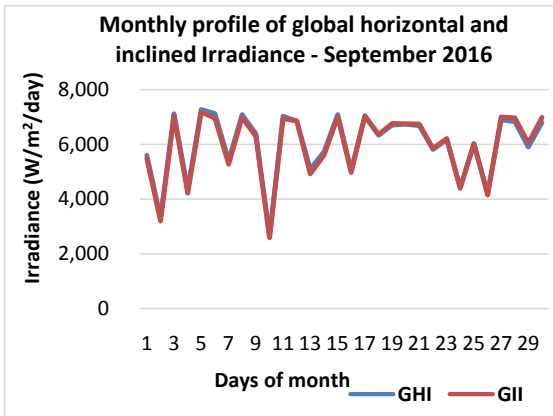

(i)

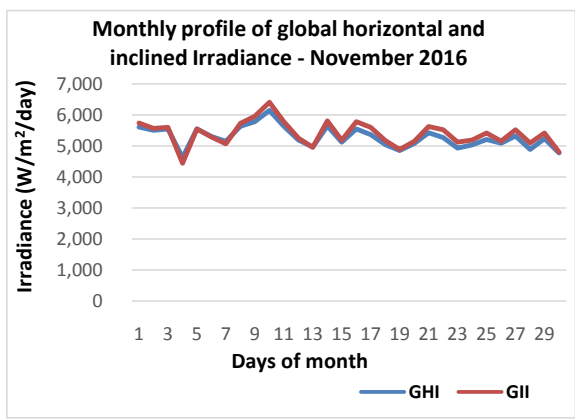

(k)

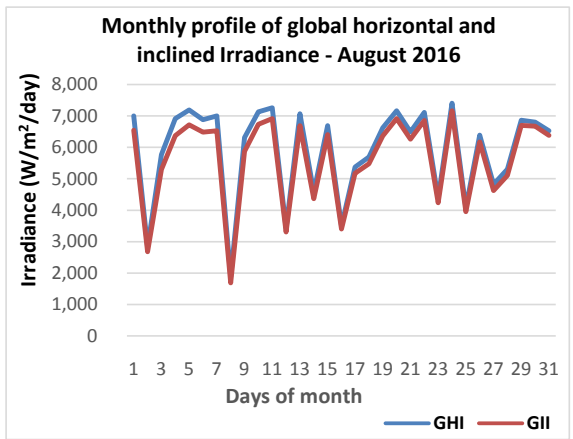

(h)

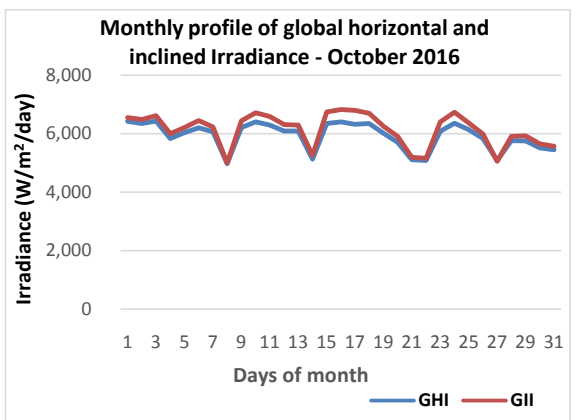

(j)

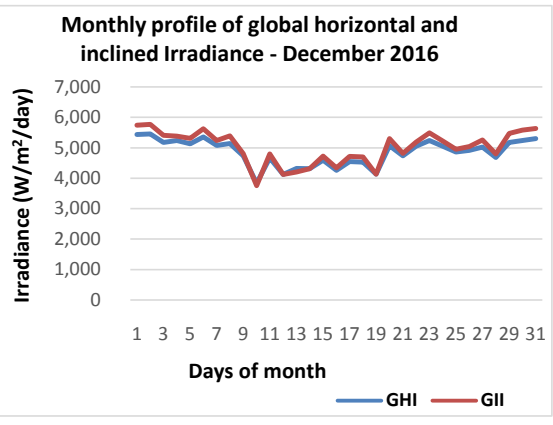

(1)

Figure 14. (a)-(1): Daily variation of the total sunning on a horizontal plane and on a tilted plane $\left(15^{\circ}\right)$ in 2015 .

January to February, GII is above that representing sunning on the horizontal plane (GHI). There is a gradual decrease in GII elevation over GHI. Towards the end of March to beginning of April, the two curves coincide. Towards the end of April, the phenomenon begins to reverse: the GHI is above that of the sunning on the inclined plane (GII) until the beginning of September. Towards the end of September to the beginning of October, the two curves merge. Towards the end of October, the phenomenon is reversed again: the sunning curve on the inclined plane (GII) is above that of the sunning on the horizontal plane until the end of December.

As shown in Figure 11 the phenomenon can be classified in two periods. One period when GII is above GHI, it is from September to March. During this period a solar panel in tilted position of $15^{\circ}$ receives more solar energy than a solar 
panel on a horizontal plane. The other period, when GII is below GHI, it is from March to mid-September. During this period the plane sensor receives more irradiation than a tilted sensor of $15^{\circ}$.

While referring to the ecliptic trajectory of the earth around the sun, the first period corresponds to the moments when the sun is in a position closer to the earth (from September to March) and the second period at the times when the sun is further away from the earth (March-September). It is also noted that when the variation is maximum March $21^{\text {st }}$, September $22^{\text {nd }}$, the two curves confused. When this variation is worthless both curves are alternate with a maximum of variation (Figure 12).

These figures show that the optimization of a solar panel depends on the season of the year and its angle of inclination. A fixed slope is perhaps not the good option for a maximum exploitation of a solar panel. A sensor provided with a solar follower is much more profitable.

\section{Conclusions}

The evaluation of the solar potential of Niamey, over the years 2015 and 2016, shows that this potential is enormous. The sunning varies between $5.1 \mathrm{kWh} / \mathrm{m}^{2}$ and $6.3 \mathrm{kWh} / \mathrm{m}^{2}$. The months of December, January and August are the least sunny, while those of April, May, September and October are the sunniest. The duration of average insolation is between 8 to 9 hours. The sunning depends on the weather conditions. It is attenuated by the clouds and the aerosols contained in the atmosphere.

The recorded considerable irradiations, the determined strong average insolation and the acceptable values of the clearness index of our site of study confirm the importance of the solar radiation of Niamey area [6] [9]. The results obtained through our measurements show that Niamey has a considerable solar potential despite the disturbances of clouds and dust. This sunning allows many energy applications mainly: photovoltaic and thermal. Niamey solar potential is comparable to that of Nouakchott and Dakar obtained by B. Ould Bilal et al. (2007) also located in the Sahelian band [8].

The limited exploitation of less than $10 \%$ of this potential per day could make it possible to fully cover Niger's annual energy needs. Solar energy could serve as a lever of Niger's economic development.

\section{References}

[1] Yahya, A.O.M. and Youm, O.A.M.I. (2008) Study and Modeling of a Photovoltaic Generator. Revue of Renewable Energies, 11, 473-448.

[2] Colleen, S. (2009) Renewable Energy Teaching Manual. 123. http://www.electronique-diffusion.fr/dl/manuel_\%20enseignement.pdf

[3] Africa Progress Panel (2015) Energy, Planet and Population. 2015 Progress Report on Africa, Africa Progress Panel, Geneva.

[4] Lahache, C. (2017) Solar Energy. 10. http://claude.lahache.free.fr/coursts1elpartie/energie-solaire.pdf 
[5] Ould Bilal, B., Sambou, V., Kebe, C.M.F., Ndongo, M. and Ndiaye, P.A. (2007) Study and Modeling of the Solar Potential of the Nouakchott and Dakar Sites. Science, 7, 57-66.

[6] Dankassoua, M., Madougou, S., Aboubacar, A. and Foulani, A. (2017) Study of the Global Solar Radiation in Niamey from the Pre-Monsoon and the Monsoon Period of the Year 2013 (May to October). Review of Renewable Energies, 20, 131-146.

[7] Cree of the Stork (CDC) (2009) Energy Balance and Prospects for an Ambitious Energy Policy in Niger. 27 Pages.

http://www.cridecigogne.org/sites/default/files/Bilan-et-perspectives-energetiques-a u-Niger-Par-CrideCigogne.pdf

[8] Ould Bilal, B., Sambou, V., Kébé, C.M.F., Ndongo, M. and Ndiaye, P.A. (2007) Study and Modeling of the Solar Potential of the Nouakchott and Dakar Sites. Journal of Sciences, 7, 57-66.

[9] Bonkaney, A., Madougou, S. and Adamou, R. (2017) Impacts of Cloud Cover and Dust on the Performance of Photovoltaic Module in Niamey. Journal of Renewable Energy, 2017, 9. https://doi.org/10.1155/2017/9107502

[10] Trahi, F. (2011) Prediction of Global Solar Irradiation for the Tizi Ouzou Region by Artificial Neural Networks: Application for the Sizing of a Photovoltaic Installation for the Supply of the Research Laboratory LAMPA. Memory of Magister in Electronics, Mouloud Mammeri University of Tizi Ouzou, Algeria, 113.

[11] Kipp \& Zonen (2012) Pyranometer CMP 3, V1007 User Manual. http://www.kippzonen.com/

[12] Kipp \& Zonen (2015) METEON Data Logger Manual. 13 Pages. http://www.kippzonen.fr/Download/108/METEON-data-logger-Manual 